\title{
Relationship between Creep Strength and Magnetic Properties of Cobalt-bearing High Chromium Ferritic Steel
}

\author{
Shigeto YAMASAKI, ${ }^{*}$ Masatoshi MITSUHARA and Hideharu NAKASHIMA \\ Department of Engineering Sciences for Electronics and Materials, Kyushu University, 6-1 Kasuga-kouen, Kasuga, Fukuoka, \\ 816-8580 Japan. \\ (Received on May 28, 2020; accepted on July 8, 2020; originally published in Tetsu-to-Hagané, Vol. 106, \\ 2020, No. 11, pp. 788-798; J-STAGE Advance published date: October 28, 2020)
}

\begin{abstract}
In this study, the relationship between changes in the magnetic properties and creep strength with the addition of 3 or 6 mass $\%$ Co was investigated for ferritic steel containing 15 mass $\%$ Cr. Co addition up to 6 mass \% hardly contributed to solid solution strengthening or precipitation strengthening at room temperature. However, in the range of 650 to $750^{\circ} \mathrm{C}$, the steel with the larger amount of Co exhibited higher creep strength, which is explained by a reduction in the diffusion rate associated with a change in magnetic properties by $\mathrm{Co}$ addition. An increase of the volume magnetization of the steel with increasing Co content in the range from room temperature to about $800^{\circ} \mathrm{C}$ was confirmed. Comparing the difference in volume magnetization and the ratio of the creep strain rate for steels with different amounts of Co, a clear correlation was found. That is, at the temperature at which the difference in volume magnetization reached a maximum, the peak of the creep strain rate ratio was also observed. This result is explained as follows. In a low temperature region where the magnetization is large or in a high temperature region above the Curie point of both steels, the steels exhibit no significant difference in the creep strength. However, at a temperature where one steel loses its ferromagnetism but the other steel retains it, a significant difference in the creep strength is observed.
\end{abstract}

KEY WORDS: ferritic steel; creep; cobalt; magnetic properties; Curie temperature; diffusion.

\section{Introduction}

Pure iron exhibits ferromagnetism below the magnetic transformation temperature of $\sim 770^{\circ} \mathrm{C}$ and paramagnetism above that temperature. The magnetic transformation of iron and its alloys has a large effect on diffusion, and the diffusion constant and its temperature dependence change in the ferromagnetic and paramagnetic regions. ${ }^{1-4)}$ Creep resistance is also known to decrease in the paramagnetic region and in the temperature range just below the magnetic transformation temperature in response to changes in magnetic properties. ${ }^{5)}$ In the ferromagnetic state, excess binding energy is generated between atoms due to the interaction between spins, and in this state, local demagnetization is required to form and move vacancies. Therefore, it is understood that the anomaly of diffusion in the ferromagnetic region is due to the extra activation enthalpy of diffusion required compared to the paramagnetic region. ${ }^{6-9)}$ The magnetic transformation temperature is the temperature at which ferromagnetism disappears completely due to thermal disturbance. In reality, the magnetization gradually decreases from lower temperatures

\footnotetext{
* Corresponding author: E-mail: yamasaki.shigeto.259@m.kyushu-u.ac.jp
}

toward the magnetic transformation temperature. Therefore, there is a transition region for the diffusion rate referred to as the Curie zone in the ferromagnetic temperature range, and anomalous diffusion rates are observed over a certain temperature range. ${ }^{9)}$ Kucera et al. ${ }^{10)}$ described the correlation between the excessive activation enthalpy of diffusion and the spontaneous magnetization in the ferromagnetic region. Therefore, it is appropriate to understand the effect of magnetic properties on diffusion based on changes in the magnitude of magnetization, rather than discussing whether the material is in the ferromagnetic or paramagnetic state.

The fact that the diffusion rate changes in relation to the magnetic properties seems to be an important aspect of creep deformation when the diffusion rate dominates the strength. The effect of magnetic transformation on the diffusion rate has been described in a textbook on heat-resistant steel $^{11)}$ and review papers. ${ }^{12,13)}$ Gustafson et al. ${ }^{14)}$ reported a study focusing on the effect of magnetic properties on the creep strength of a practical ferritic heat-resistant steel, but to our best knowledge, there are very few studies from such a perspective. This may be related to the fact that conventional ferritic heat-resistant steel is typically used in the ferromagnetic range. For example, at present, the 
maximum operating temperature for a steam pipe in a thermal power generation boiler, in which conventional ferritic heat-resistant steel containing 9-12 mass $\% \mathrm{Cr}$ is applied, is approximately $620^{\circ} \mathrm{C} .{ }^{15,16)}$

One of the features of the chemical composition of next-generation ferritic heat-resistant steels that have been developed in recent years for applications at temperatures above $650{ }^{\circ} \mathrm{C}$ is the addition of $\mathrm{Co}$ in $\sim 3$ mass $\%{ }^{17-21)}$ All these ferritic heat-resistant steels have a tempered lath martensite structure; to form this microstructure, it is necessary to transform the material to austenite at the normalizing temperature and then transform it to martensite during cooling. However, in these new steels, the amount of $\mathrm{W}$ added is increased with the intention of improving the creep strength, so the ferrite-stabilizing effect of $\mathrm{W}$ suppresses austenite transformation at high temperatures. As a result, the residual $\delta$-ferrite diminishes the toughness of the steel. In these new steels, Co addition is expected to suppress the formation of residual $\delta$-ferrite due to its high austenite stabilizing effect. ${ }^{18)}$ Thus, the main purpose of adding Co to these new steels is not necessarily creep strengthening.

Although Co addition has been reported as effective for creep strengthening in ferritic heat-resistant steels, ${ }^{14,22-28)}$ its effectiveness depends on the composition of the steel or the temperature and time of the creep test. ${ }^{29-34)}$ With respect to chemical composition, Co addition was effective for creep strengthening in heat-resistant steels with $\mathrm{Cr}$ contents of 9 or 15 mass $\%,{ }^{14,22-28)}$ but in these cases, the samples had a single-phase martensite or ferrite structure. In contrast, several other studies concluded that the addition of Co was not effective for creep strengthening, but these investigations were conducted on heat-resistant steels with 10.5-12 mass\% $\mathrm{Cr}$ contents that contained residual $\delta$ ferrite in part of the martensitic microstructure..$^{29,30,33)}$

It is well known that Co raises the magnetic transformation temperature of iron, and it has been reported that Co-bearing steel exhibits a significantly reduced diffusion rate just below the magnetic transformation temperature. ${ }^{8)}$ Considering this fact, then, one of the factors for creep strengthening by the addition of Co to ferritic heat-resistant steel is the reduction of the diffusion rate. However, few studies ${ }^{14,28)}$ have referred to this phenomenon, and the understanding of creep strength from the perspective of the change in magnetic properties due to the addition of Co to ferritic heat-resistant steel has not advanced. Currently, next-generation ferritic heat-resistant steels that can be used at $700^{\circ} \mathrm{C}$ are being developed, ${ }^{35,36)}$ wherein the $\mathrm{Cr}$ content is increased to 15 mass $\%$ to improve their oxidation resistance. Figure 1 shows the changes in magnetic transformation temperature $T_{\mathrm{C}}$ when $\mathrm{Cr}$ or $\mathrm{Co}$ is added to pure iron, as obtained by thermal equilibrium calculations. These results show that $\mathrm{Cr}$, which is added in a large amount to the ferritic heat-resistant steel and has a large solid solution limit, significantly reduces the $T_{\mathrm{C}}$ of iron. In other words, in the next-generation steels of this type, as the operating temperature rises to $700^{\circ} \mathrm{C}$ and $T_{\mathrm{C}}$ decreases due to the increasing $\mathrm{Cr}$ content, the operating environment approaches the paramagnetic region. As also shown in Fig. 1, Co significantly increases the $T_{\mathrm{C}}$ of iron. This suggests that the addition of Co may shift the ferromagnetic region (having a low diffusion rate) to a higher temperature, and as a result, may increase the creep strength in that temperature range. Thus, if the change in magnetic properties due to the addition of $\mathrm{Co}$ affects the creep strength of the steel, the effect will become more apparent in a next-generation ferritic heat-resistant steel that is expected to be applied at $700^{\circ} \mathrm{C}$ or higher.

The purpose of this study was to clarify the relationship between the change in magnetic properties and the creep strength with the addition of Co in ferritic steels containing 15 mass $\% \mathrm{Cr}$, which is equivalent to a next-generation ferritic heat-resistant steel. In addition, the temperature at which creep strengthening by the Co addition is most effective in the present steels was clarified.

\section{Experimental}

Samples containing 15 mass $\% \mathrm{Cr}$ (hereinafter, $15 \mathrm{Cr}$ steel) and steels containing 3 or 6 mass $\%$ Co (hereinafter, $15 \mathrm{Cr}-3 \mathrm{Co}$ steel and $15 \mathrm{Cr}-6 \mathrm{Co}$ steel) were prepared. Each material was melted in a high frequency induction melting furnace and cast into an ingot of about $5 \mathrm{~kg}$. Chemical composition analysis was performed on the cut surface of each ingot; the results are presented in Table 1. The data confirm that the target amounts of $\mathrm{Cr}$ and Co were achieved, and other impurity elements including $\mathrm{C}$ were suppressed to low levels. Each ingot was heated at $1200^{\circ} \mathrm{C}$ for $1 \mathrm{~h}$ and then hot rolled. The hot-rolled material was further cold rolled. After cold rolling, the $15 \mathrm{Cr}$ and $15 \mathrm{Cr}-3 \mathrm{Co}$ steels were heat-treated at $800^{\circ} \mathrm{C}$ for $2 \mathrm{~h}$. The $15 \mathrm{Cr}-6 \mathrm{Co}$ steel was heat-treated at $1200^{\circ} \mathrm{C}$ for $10 \mathrm{~h}$, cooled in a furnace at $90^{\circ} \mathrm{C} / \mathrm{h}$ to $750^{\circ} \mathrm{C}$, and further heat-treated at $750^{\circ} \mathrm{C}$ for $24 \mathrm{~h}$. Scanning electron microscope (SEM, Carl Zeiss ULTRA55)

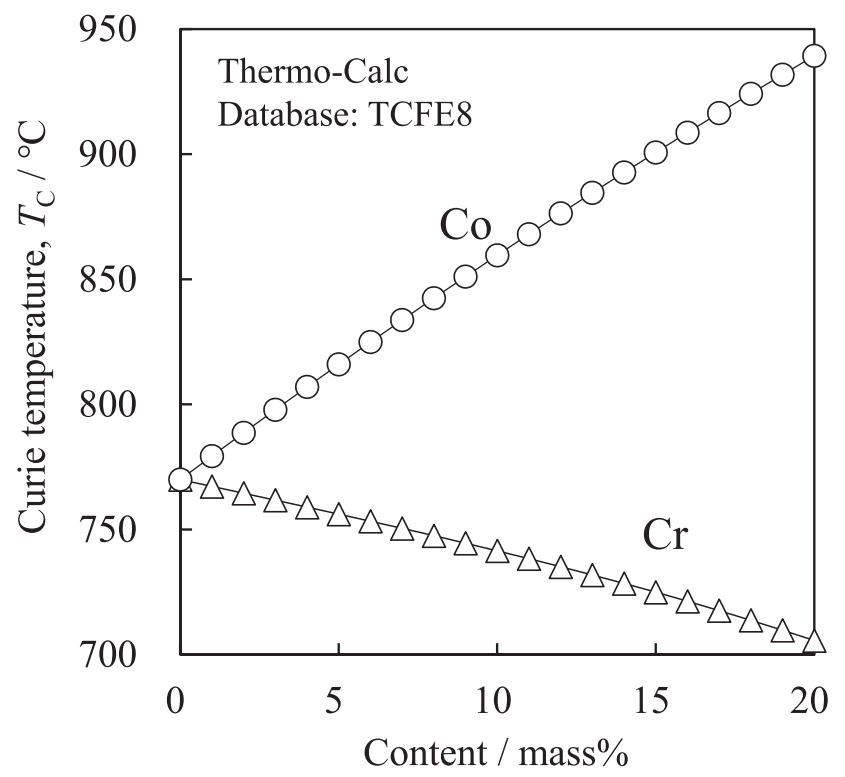

Fig. 1. Curie temperature $\left(T_{\mathrm{C}}\right)$ change by addition of $\mathrm{Cr}$ or $\mathrm{Co}$ to Fe calculated using Thermo-Calc software.

Table 1. Chemical composition (mass $\%$ ).

\begin{tabular}{ccccccccc}
\hline & Fe & $\mathrm{Cr}$ & $\mathrm{Co}$ & $\mathrm{C}$ & $\mathrm{Mn}$ & $\mathrm{Si}$ & $\mathrm{S}$ & $\mathrm{P}$ \\
\hline $15 \mathrm{Cr}$ & bal. & 14.89 & $<0.01$ & 0.0014 & $<0.01$ & 0.01 & $<0.001$ & $<0.002$ \\
$15 \mathrm{Cr}-3 \mathrm{Co}$ & bal. 14.90 & 3.00 & 0.0010 & $<0.01$ & 0.02 & $<0.001$ & $<0.002$ \\
$15 \mathrm{Cr}-6 \mathrm{Co}$ & bal. 14.88 & 6.04 & 0.0018 & $<0.01$ & 0.02 & $<0.001$ & $<0.002$ \\
\hline
\end{tabular}


was used to observe the microstructures of the samples. For SEM observation, samples of the heat-treated materials were cut into small pieces and polished to a mirror finish. Then, mechano-chemical polishing using colloidal silica was carried out for $\sim 90$ min to remove surface strain. In the SEM observations, a backscattered electron (BSE) image was adopted. In addition, crystal orientation mapping by the electron backscattered diffraction (EBSD) method and elemental composition analysis by energy dispersive X-ray spectroscopy (EDS) were also performed. These observations and measurements were carried out at an accelerating voltage of $15 \mathrm{kV}$ and a working distance of 8.5 to $15 \mathrm{~mm}$. To estimate the contributions of $\mathrm{Cr}$ and $\mathrm{Co}$ addition to solid solution strengthening, lattice constants were measured on the samples polished for SEM observation by X-ray diffraction (XRD, Rigaku SmartLab SE diffractometer). Co $\mathrm{K} \alpha$ radiation operating at $40 \mathrm{kV}$ and $25 \mathrm{~mA}$ was used for the measurement and $\mathrm{Co} \mathrm{K} \beta$ radiation was removed by an $\mathrm{Fe}$ filter. The diffraction profiles were obtained by varying $2 \theta$ from $50^{\circ}$ to $130^{\circ}$ with a scan speed of $1 \% \mathrm{~min}$ and a scan step of $0.01^{\circ}$ using a high-speed one-dimensional X-ray detector.

The hardness of the samples was measured by the Vickers hardness test. An indenter was pressed into 16 points on the polished surface of the SEM observation sample with a load of $0.2 \mathrm{kgf}$. The size of the indentation was approximately 50 $\mu \mathrm{m}$. Since the minimum grain size of the Co-added high chromium steel used in this study is about $100 \mu \mathrm{m}$, the hardness evaluated in this experiment is the value of that within the ferrite grains. The average of the measured values was calculated, and the standard deviation was described as the error.

Differential scanning calorimetry (DSC) was performed to measure the austenite transformation $\left(\mathrm{A}_{\mathrm{c} 1}\right)$ temperature and magnetic transformation temperature $T_{\mathrm{C}}$. Pieces $(\sim 100$ $\mathrm{mg}$ ) cut from the cold-rolled material were used as samples for DSC measurement. The surface of the DSC sample that contacted the sample pan was smoothed by polishing. A pan made of a composite material of platinum-rhodium alloy and alumina was used as a reference sample. The measurement was performed in the range of 600 to $900^{\circ} \mathrm{C}$ at a heating/cooling rate of $10^{\circ} \mathrm{C} / \mathrm{min}$. During the measurement, Ar gas was swept at a flow rate of $20 \mathrm{~mL} / \mathrm{min}$ to prevent sample oxidation.

The magnetization of the sample steel was measured using a vibrating sample magnetometer (VSM, model BHV-5, Riken Denshi Co., Ltd.). A sample of about $5 \times$ $5 \times 1 \mathrm{~mm}^{3}$ was acquired from the cold-rolled material for each steel. Magnetization-field (M-H) curves were measured by applying a maximum magnetic field of $398 \mathrm{kA} / \mathrm{m}(5$ $\mathrm{kÖe}$ ) at room temperature. In addition, the magnetization of the sample in an applied magnetic field of $398 \mathrm{kA} / \mathrm{m}$ was measured in vacuum from room temperature to $800^{\circ} \mathrm{C}$ at a heating rate of $5^{\circ} \mathrm{C} / \mathrm{min}$.

A uniaxial tensile creep test was performed on each sample. A cylindrical creep test piece with a gauge length of $30 \mathrm{~mm}$ was prepared from the heat-treated material. The creep test was started after holding at the test temperature for $2-12 \mathrm{~h}$ in order to stabilize the temperature of the entire testing system. The displacement was measured using a linear gauge with a displacement resolution of $1 \mu \mathrm{m}$ via an extensometer attached to the test piece. The creep tests were conducted at $650,675,700,715,725$, and $750^{\circ} \mathrm{C}$ with a load stress of $20 \mathrm{MPa}$. In addition, the $15 \mathrm{Cr}$ and $15 \mathrm{Cr}-6 \mathrm{Co}$ steels were tested at 775 and $800^{\circ} \mathrm{C}$. The creep test was performed until the test piece broke or the accelerated creep region was reached.

\section{Results and Discussion}

\subsection{Microstructure}

Figure 2 shows the DSC curves for the $15 \mathrm{Cr}, 15 \mathrm{Cr}-3 \mathrm{Co}$, and $15 \mathrm{Cr}-6 \mathrm{Co}$ steels with increasing temperature from 600 to $850^{\circ} \mathrm{C}$. The magnetic transformation appears as an endothermic peak during the heating phase of the DSC measurement. ${ }^{37,38)}$ Endothermic peaks observed at $708^{\circ} \mathrm{C}$ for $15 \mathrm{Cr}$ steel, $723^{\circ} \mathrm{C}$ for $15 \mathrm{Cr}-3 \mathrm{Co}$ steel, and $733^{\circ} \mathrm{C}$ for $15 \mathrm{Cr}-6 \mathrm{Co}$ steel correspond to their respective magnetic transformations. The second endothermic peak observed at $770^{\circ} \mathrm{C}$ in $15 \mathrm{Cr}-6 \mathrm{Co}$ steel is due to austenite transformation; the heat treatment conditions for $15 \mathrm{Cr}-6 \mathrm{Co}$ steel were determined based on this temperature (the $A_{c 1}$ point). Since no peaks corresponding to $\mathrm{A}_{\mathrm{c} 1}$ are observed in the $15 \mathrm{Cr}$ and $15 \mathrm{Cr}-3 \mathrm{Co}$ steels, both likely maintain the ferrite single phase, even at temperatures as high as $900^{\circ} \mathrm{C}$, which is the upper temperature limit for the DSC measurement.

SEM observations were performed to inspect the microstructure. Figure 3 shows the crystal orientation map for each steel obtained by SEM-EBSD measurement. The $15 \mathrm{Cr}$ and $15 \mathrm{Cr}-3 \mathrm{Co}$ steels have structures composed of coarse ferrite grains, with grain sizes of $\sim 300$ to $800 \mu \mathrm{m}$. In comparison, the $15 \mathrm{Cr}-6 \mathrm{Co}$ steel has slightly finer crystal grains, and martensite grains are also observed. Figure 4 shows the SEM-BSE image of $15 \mathrm{Cr}-6 \mathrm{Co}$ steel, which confirms that the ferrite and martensite grains are mixed. The area ratio of the martensite grains in this image was evaluated as $39.7 \%$. Each sample contains inclusions, as indicated by the white arrows in Fig. 4; these were identified as $\mathrm{Cr}$ oxides by EDS elemental analysis. The amounts and sizes of these $\mathrm{Cr}$ oxides are similar in the three steel types, and since they are coarse and sparsely dispersed, they are considered to have little effect on strength. The absence of second phase par-

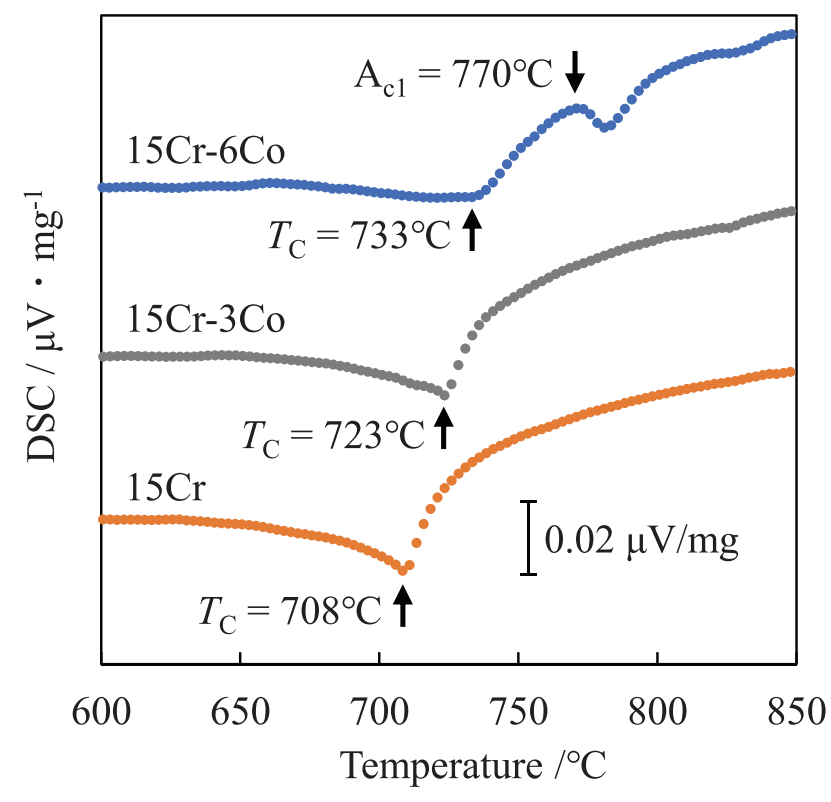

Fig. 2. DSC curves during heating. (Online version in color.) 

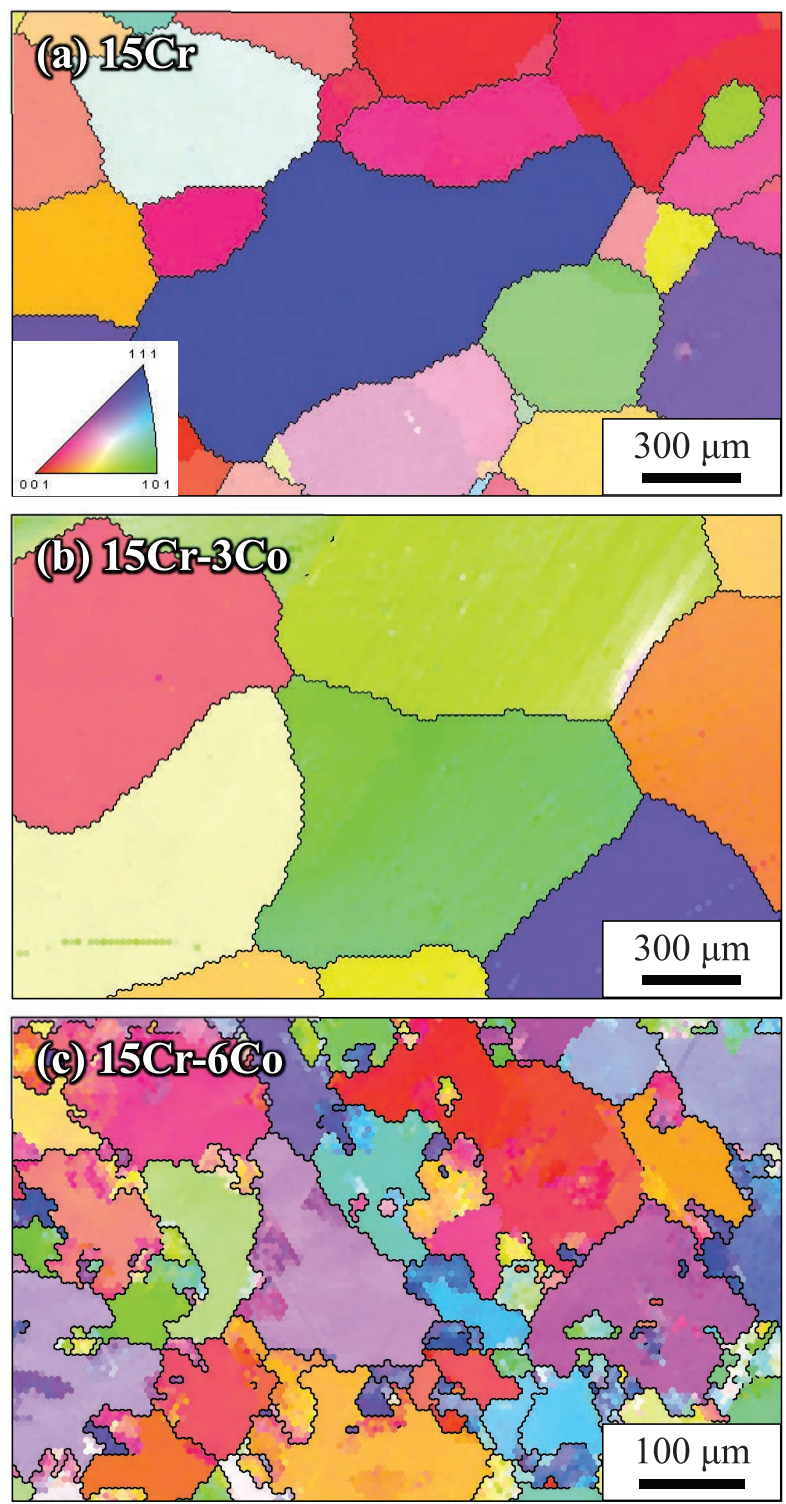

Fig. 3. Crystal orientation maps of (a) $15 \mathrm{Cr}$, (b) $15 \mathrm{Cr}-3 \mathrm{Co}$, and (c) $15 \mathrm{Cr}-6 \mathrm{Co}$ after annealing. (Online version in color.)

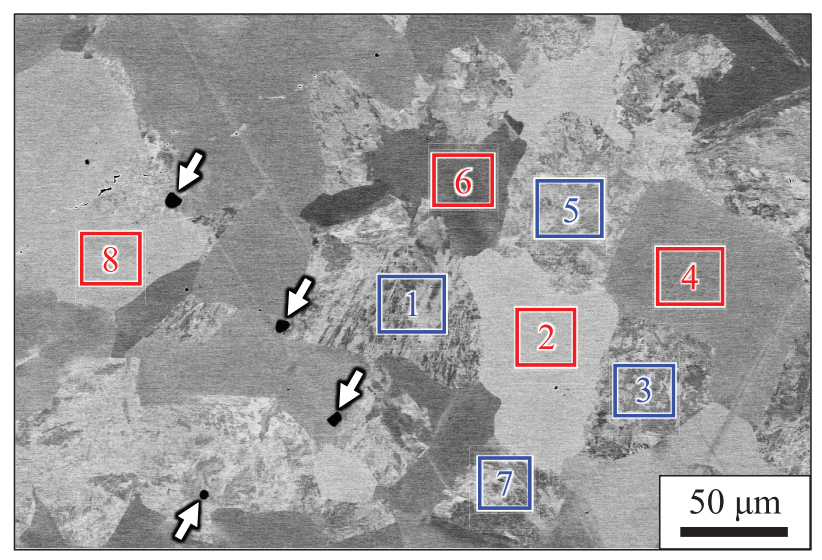

Fig. 4. SEM-BSE image of $15 \mathrm{Cr}-6 \mathrm{Co}$. The rectangles represent the areas where EDS analysis was performed. (Online version in color.)

ticles other than the $\mathrm{Cr}$ oxide in the sample steels confirms that no precipitation phase was formed by the addition of $\mathrm{Cr}$ or Co. Table 2 summarizes the results of the EDS quantita-
Table 2. Chemical composition of ferrite and martensite in $15 \mathrm{Cr}-6 \mathrm{Co}$ measured by SEM-EDS (mass\%).

\begin{tabular}{ccccccc}
\hline \multirow{5}{*}{ Ferrite } & & area 2 & area 4 & area 6 & area 8 & avg. \\
\cline { 2 - 7 } & $\mathrm{Fe}$ & 76.9 & 77.0 & 77.1 & 78.1 & 77.3 \\
& $\mathrm{Cr}$ & 17.2 & 16.5 & 16.6 & 14.7 & 16.2 \\
& $\mathrm{Co}$ & 5.9 & 6.5 & 6.3 & 7.2 & 6.5 \\
\hline \multirow{5}{*}{ Martensite } & $\mathrm{Fe}$ & 78.5 & 79.1 & 78.9 & 78.6 & 78.8 \\
& $\mathrm{Cr}$ & 13.4 & 13.3 & 13.4 & 13.7 & 13.4 \\
& $\mathrm{Co}$ & 8.1 & 7.7 & 7.7 & 7.7 & 7.8 \\
\hline
\end{tabular}

tive analyses performed on the ferrite grains (red frames) and martensite grains (blue frames) in the regions indicated by the rectangles in Fig. 4. The ferrite grains contain $\sim 16$ mass $\% \mathrm{Cr}$ and $\sim 6.5$ mass $\%$ Co, while the martensite grains contain $\sim 13$ mass $\% \mathrm{Cr}$ and $\sim 7.8$ mass $\% \mathrm{Co}$. It is understood that this difference in concentration occurs because Co is concentrated in the austenite grains and $\mathrm{Cr}$ is discharged to the ferrite grains at $1200^{\circ} \mathrm{C}$, at which the matrix consists of a ferrite-austenite dual phase. It is understood that the austenite grains remain after the heat treatment at $750^{\circ} \mathrm{C}$ for 24 $\mathrm{h}$ due to this difference in concentration, and the martensite transformation occurs when air-cooled to room temperature. In creep deformation, coarse-grained materials with few grain boundaries that act as short circuit diffusion paths have higher creep resistance. ${ }^{39,40)}$ Therefore, the microstructure of $15 \mathrm{Cr}-6 \mathrm{Co}$ steel, with a matrix composed of fine ferrite and martensite grains, is inferior in creep strength to the other two steels in terms of the matrix microstructure.

\subsection{Effect of $\mathrm{Cr}$ and Co Addition on Solid Solution Strengthening}

Figure 5 shows a comparison of XRD line profiles near the 211 peak. Since the peak positions are almost the same among the steels, the change in lattice constant due to the addition of Co is extremely small. Table 3 shows the lattice constants calculated from the 211 peak positions. The lattice constants of the sample steels are $\sim 0.28725 \mathrm{~nm}$, which is $\sim 6.0 \times 10^{-4} \mathrm{~nm}$ larger than the lattice constant of pure iron $(0.28664 \mathrm{~nm}){ }^{41)}$ Calculating the rate of change in the lattice constant of iron due to the solid solution of $\mathrm{Cr}$ as $+5.5 \times$ $10^{-5} \mathrm{~nm}$ per $\mathrm{mol} \%{ }^{42)}$ affords a value of $+8.9 \times 10^{-4} \mathrm{~nm}$ at 15 mass $\%(16.1 \mathrm{~mol} \%)$, which nearly agrees with the measurement result. The rate of change in the lattice constant of iron due to the solid solution of Co is reported to be $+0.8 \times 10^{-5}$ $\mathrm{nm}^{42)}$ per $\mathrm{mol} \%$, and the change in the lattice constant when 6 mass $\%(5.7 \mathrm{~mol} \%)$ is added is $+0.5 \times 10^{-4} \mathrm{~nm}$. Since this value is very small, that the measured lattice constants are quite similar regardless of the Co content is not unexpected. Table 3 also presents the results of the Vickers hardness tests conducted to compare the magnitude of solid solution strengthening. As described in the experimental section, the Vickers indentation size $(\sim 50 \mu \mathrm{m})$ is smaller than the average crystal grain sizes in the samples, and thus, the Vickers hardness can be regarded as the value within the ferrite grains. The Vickers hardness of each steel is about 130 HV0.2, and the hardness difference between samples with different Co contents falls within the error range. Therefore, 


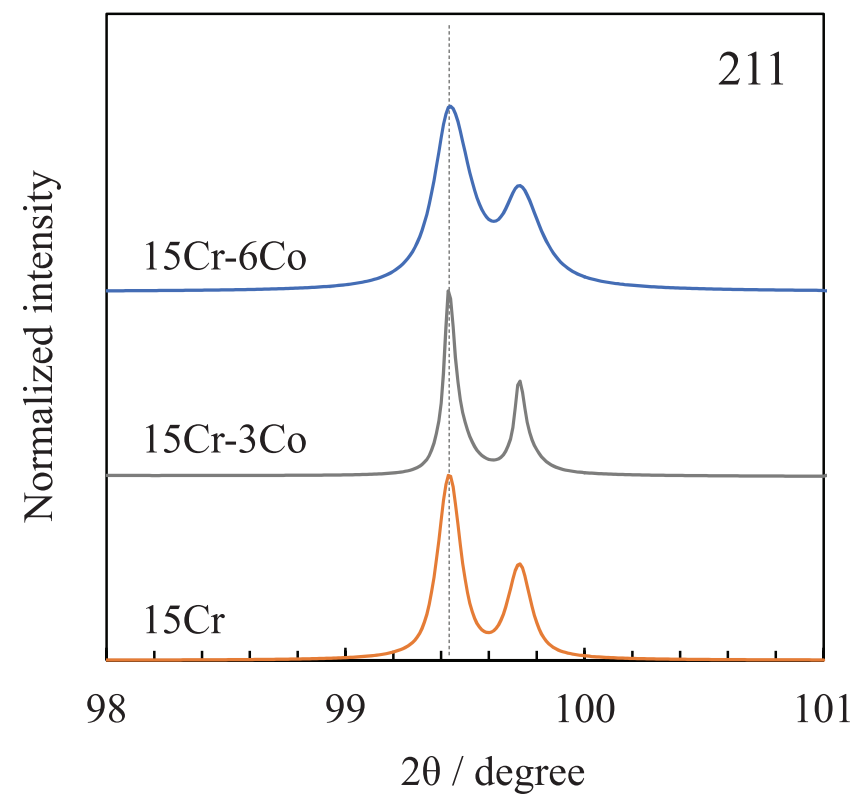

Fig. 5. XRD line profiles around the 211 diffraction peak. (Online version in color.)

Table 3. Summary of lattice constant, Vickers hardness and Curie temperature.

\begin{tabular}{ccccc}
\hline & \multirow{2}{*}{$\begin{array}{c}\text { lattice constant } \\
\text { (XRD) }[\mathrm{nm}]\end{array}$} & $\begin{array}{c}\text { Vickers } \\
\text { hardness HV0.2 }\end{array}$ & \multicolumn{2}{c}{ Curie temperature, $T_{\mathrm{C}}\left[{ }^{\circ} \mathrm{C}\right]$} \\
\hline $15 \mathrm{Cr}$ & 0.28725 & $129 \pm 3$ & 708 & 720 \\
$15 \mathrm{Cr}-3 \mathrm{Co}$ & 0.28725 & $130 \pm 3$ & 723 & 734 \\
$15 \mathrm{Cr}-6 \mathrm{Co}$ & 0.28724 & $132 \pm 3$ & 733 & 752 \\
\hline
\end{tabular}

Co addition does not substantially contribute to solid solution strengthening at room temperature, as expected from the lattice constant measurements by XRD. The diffusion rate of the solute atoms is also an important factor for solid solution strengthening by the solute drag mechanism at high temperatures. In this mechanism, elements with slower diffusion rates have greater strengthening abilities. However, since the diffusion rate of $\mathrm{Co}$ in iron is almost the same as that of the self-diffusion of iron, ${ }^{4)}$ this effect can be ignored. From these results, the effect of Co solid solution strengthening on creep strength is negligible in these three steels with different Co contents.

\subsection{Magnetic Properties}

Figure 6 shows the relationship between the volume magnetization and magnetic field for each steel. By applying an external magnetic field of $398 \mathrm{kA} / \mathrm{m}$ at maximum at room temperature, the magnetizations of all three steels become nearly saturated. Figure 6(b) presents an enlarged view of the red broken rectangle in Fig. 6(a). The maximum magnetization of the sample increases with increasing Co content at room temperature. Figure 7(a) shows the relationship between the volume magnetization and temperature from room temperature to $800^{\circ} \mathrm{C}$. The magnetization of all three steels decreases as the temperature rises; indeed, magnetism is nearly absent at $800^{\circ} \mathrm{C}$. From the enlarged view of the magnetization-temperature curves from 640 to $760^{\circ} \mathrm{C}$ shown in Fig. 7(b), it is clear that the higher the Co content, the higher the magnetization of the sample, even at high temperatures. As indicated by the arrows in Fig. 7(b), $T_{\mathrm{C}}$ can be evaluated from the intersection of the horizontal axis by the tangent line drawn from the section of the magnetizationtemperature curve with the largest gradient. The evaluated $T_{\mathrm{C}}$ are listed in Table 3 along with the values measured by DSC. The $T_{\mathrm{C}}$ values measured by VSM are $11-19^{\circ} \mathrm{C}$ higher than those by DSC. However, the $T_{\mathrm{C}}$ values evaluated by either measurement method are higher in the sample with the larger amount of $\mathrm{Co}$, and this tendency corresponds to the magnitude of the magnetization.

\subsection{Creep Deformation Behavior}

Figure 8 shows the creep strain over time curves for each steel from 650 to $750^{\circ} \mathrm{C}$. The triangular symbol represents the interruption point of the creep test. A reverse-transition-type creep curve shape, in which transition creep hardly appears, is observed under many test conditions. Figure 9 shows the strain rate-time curves at each test temperature. Due to the reverse-transition-type creep behavior described above, the decreases in strain rate in the transition creep region are small. Since the minimum strain rate at the same temperature is lower as the Co content rises, creep strengthening is caused by the addition of Co. Reverse-transition-type creep is a characteristic feature of alloys ${ }^{43}$ in which solid solution strengthening occurs due to the solute drag mechanism. Since this behavior is observed even in the $15 \mathrm{Cr}$ steel to which Co was not added, it is likely that solute drag is caused by the solid solution Cr. Although it is difficult to estimate the contribution of Co to high temperature solid solution strengthening from the creep behavior alone, by considering the lattice strain and diffusion rate mentioned above, the effect of Co on solute drag should be small compared to the effect of 15 mass $\% \mathrm{Cr}$. On the other hand, since the minimum strain rate is lowered by the addition of $\mathrm{Co}$, Co contributes to creep strengthening by some mechanism other than solute drag.

\subsection{Discussion}

Figure 10 shows the Arrhenius plots of the minimum strain rates for the three steels. In addition to the results from 650 to $750^{\circ} \mathrm{C}$, the minimum strain rates at $775^{\circ} \mathrm{C}$ for $15 \mathrm{Cr}$ steel and 775 and $800^{\circ} \mathrm{C}$ for $15 \mathrm{Cr}-6 \mathrm{Co}$ steel are also plotted in the figure. At all temperatures, steels with higher Co addition display lower minimum strain rates. In the $15 \mathrm{Cr}-6 \mathrm{Co}$ steel, the minimum strain rate at $775^{\circ} \mathrm{C}$ is smaller than that at $750^{\circ} \mathrm{C}$. From the DSC measurement results for the $15 \mathrm{Cr}-6 \mathrm{Co}$ steel, which exhibits a partial austenite transformation at $\sim 770^{\circ} \mathrm{C}$, it can be understood that the sharp decrease in the minimum strain rate in this temperature range is due to the appearance of austenite with a lower diffusion rate than that of ferrite. The slope of the Arrhenius plot corresponding to the apparent activation energy of creep deformation is not uniform from 650 to $775^{\circ} \mathrm{C}$. In $15 \mathrm{Cr}$ steel, the apparent activation energy of creep deformation evaluated from 750 to $775^{\circ} \mathrm{C}$ is $247 \mathrm{~kJ} / \mathrm{mol}$, which is close to the activation energy of the self-diffusion of iron in the paramagnetic region $(251 \mathrm{~kJ} / \mathrm{mol}){ }^{4)}$ However, the apparent activation energy of $15 \mathrm{Cr}$ steel changes drastically in the temperature range below $750^{\circ} \mathrm{C}$ and reaches a large value of $624 \mathrm{~kJ} / \mathrm{mol}$ from 650 to $725^{\circ} \mathrm{C}$. The apparent acti- 

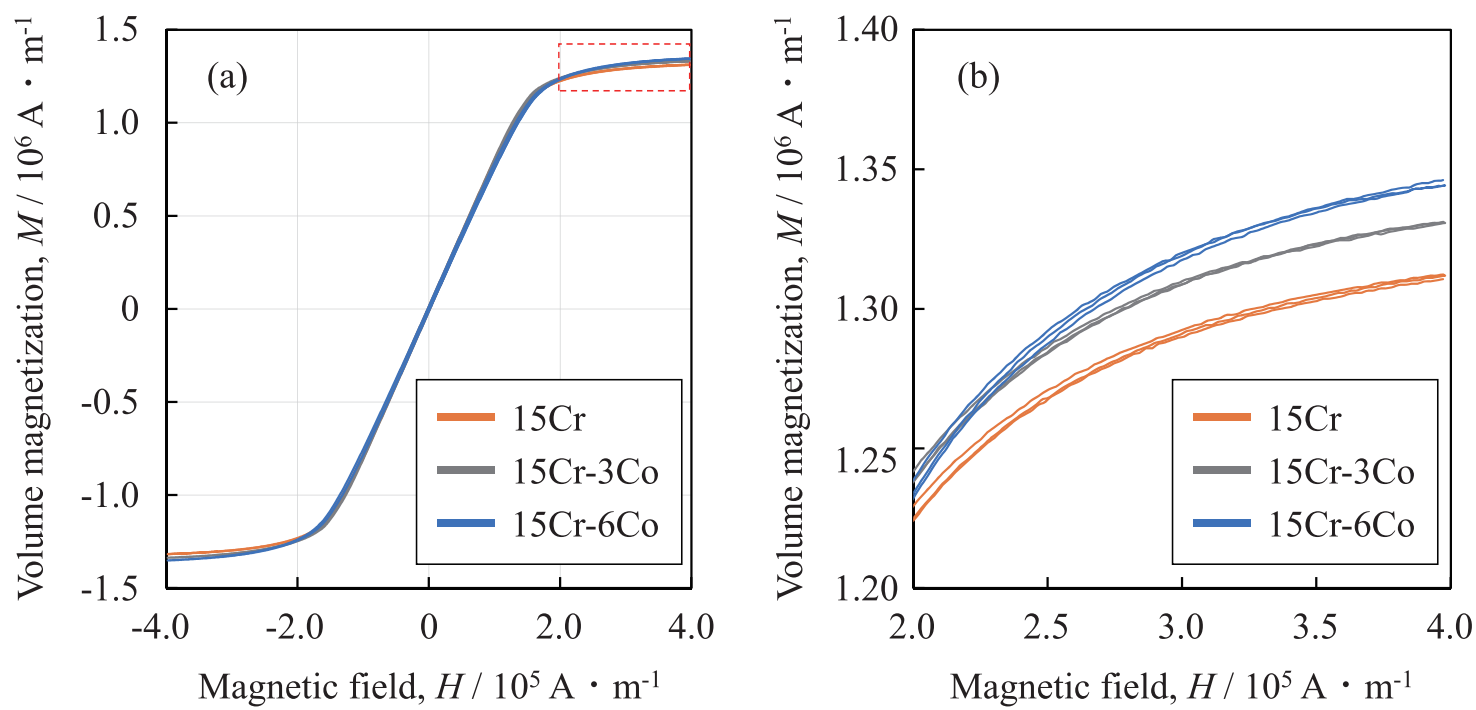

Fig. 6. M-H curves at room temperature. (a) Whole curves and (b) enlarged view of the rectangle shown in (a).
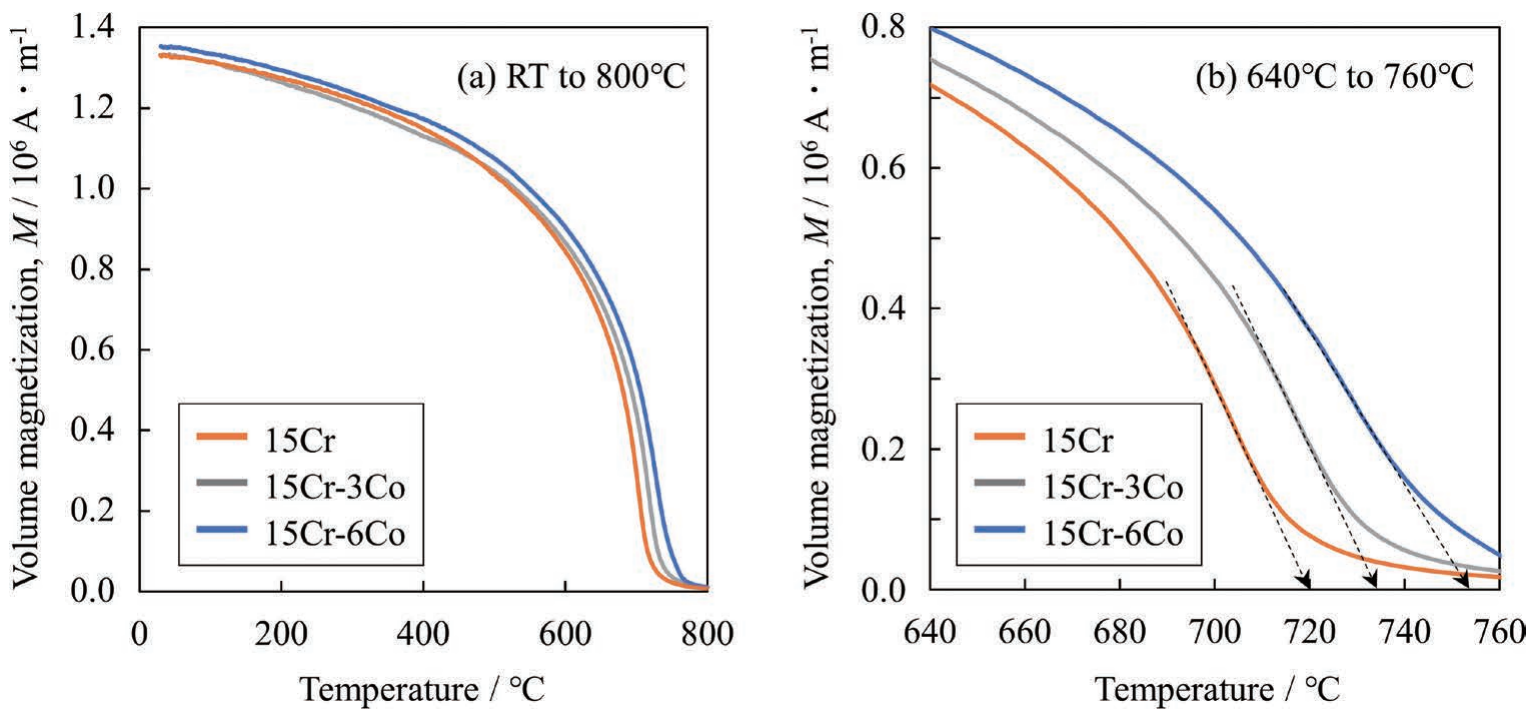

Fig. 7. Magnetization-Temperature curves (a) from room temperature to $800^{\circ} \mathrm{C}$ and (b) an enlarged view from 640 to $760^{\circ} \mathrm{C}$.

vation energies of $15 \mathrm{Cr}-3 \mathrm{Co}$ and $15 \mathrm{Cr}-6 \mathrm{Co}$ steels are also larger than those of iron self-diffusion. The values change at $\sim 690^{\circ} \mathrm{C}$ for $15 \mathrm{Cr}-3 \mathrm{Co}$ steel and $\sim 715^{\circ} \mathrm{C}$ for $15 \mathrm{Cr}-6 \mathrm{Co}$ steel, and are evaluated to be $\sim 1000 \mathrm{~kJ} / \mathrm{mol}$ in the higher temperature range and $\sim 500 \mathrm{~kJ} / \mathrm{mol}$ in the lower temperature range. The activation energy $Q_{f}$ for lattice diffusion in the ferromagnetic region is expressed by the formula, ${ }^{44)}$

$$
Q_{f}=Q_{p}\left(1+\alpha s^{2}\right),
$$

where $Q_{p}$ is the activation energy in the paramagnetic region (self-diffusion of iron: $251 \mathrm{~kJ} / \mathrm{mol}, \mathrm{Cr}$ diffusion in iron: 267 $\mathrm{kJ} / \mathrm{mol}$, Co diffusion in iron: $251 \mathrm{~kJ} / \mathrm{mol}$ ), $s$ is the ratio of saturation magnetization at $0 \mathrm{~K}$ and $T \mathrm{~K}$, and $\alpha$ is a constant (self-diffusion of iron: $0.156, \mathrm{Cr}$ diffusion in iron: 0.133 , Co diffusion in iron: 0.23). From this relationship, a larger activation energy can be estimated in the ferromagnetic region than in the paramagnetic region. However, even when $s=$ 1 , the activation energies of iron self-diffusion, $\mathrm{Cr}$ diffusion in iron, and Co diffusion in iron are 290, 303, and $309 \mathrm{~kJ} /$ mol, respectively. Therefore, the values estimated from the above equation cannot explain the large activation energies measured in this study. It has been reported that the apparent activation energy has an abnormally large value in the transition temperature range from the paramagnetic to the ferromagnetic region. ${ }^{9)}$ Therefore, the large activation energies measured in this study are considered to correspond to this transition.

Comparing the minimum strain rates of the three steels in the $650-750^{\circ} \mathrm{C}$ range, the difference in creep strength depends on the temperature. The difference in the minimum strain rate between the $15 \mathrm{Cr}$ and $15 \mathrm{Cr}-6 \mathrm{Co}$ steels is the smallest at $750^{\circ} \mathrm{C}$. The largest value is observed at $715^{\circ} \mathrm{C}$, and then, the difference tends to decline again at lower temperatures. In addition, the minimum strain rate of the $15 \mathrm{Cr}-3 \mathrm{Co}$ steel is always located between those of the $15 \mathrm{Cr}$ and $15 \mathrm{Cr}-6 \mathrm{Co}$ steels, but it is closer to that of $15 \mathrm{Cr}$ steel in the high temperature region and that of $15 \mathrm{Cr}-6 \mathrm{Co}$ steel in the low temperature region. To examine the factors underlying the difference in the minimum strain rate among the sample steels in correspondence with the magnitude of 

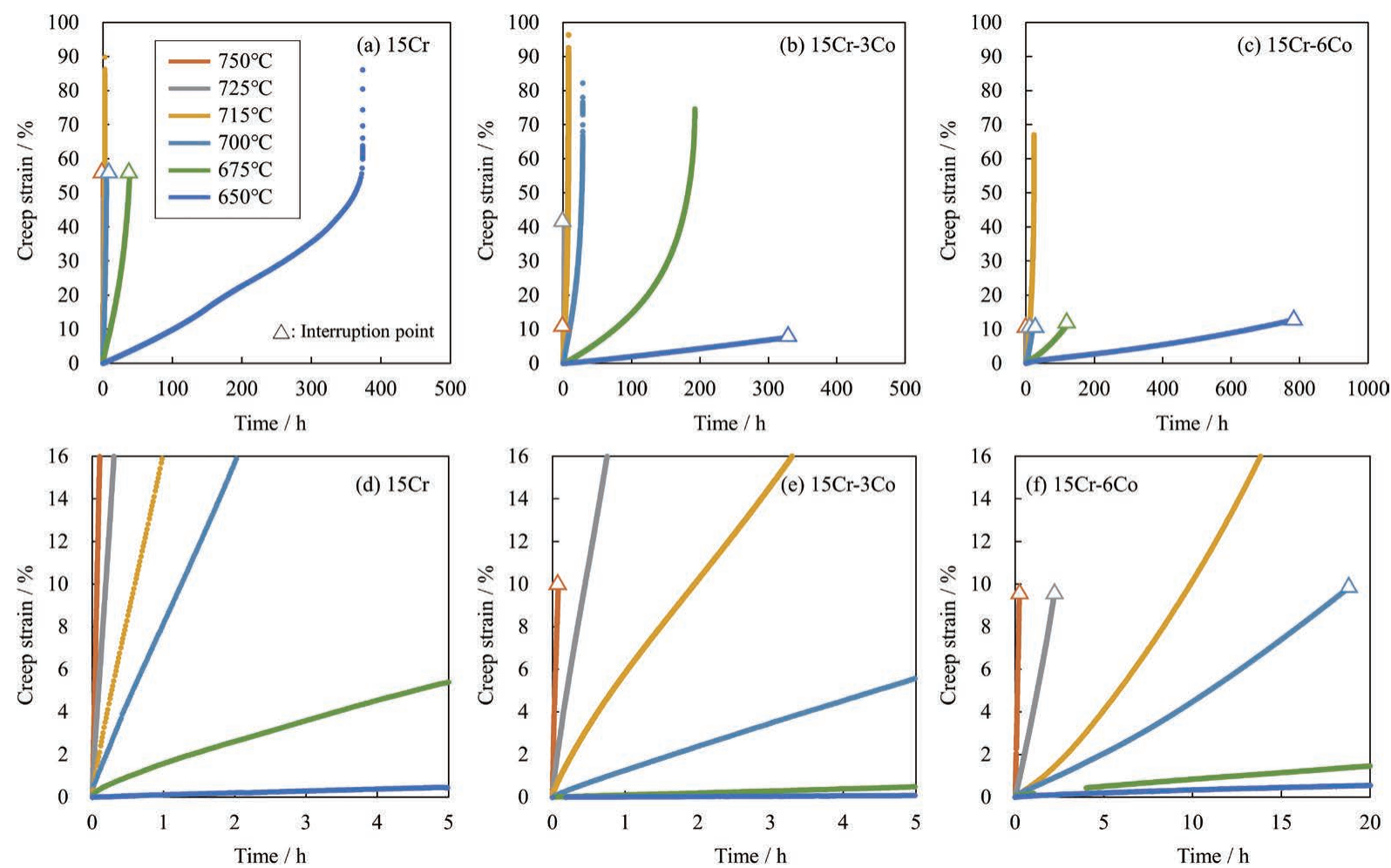

Fig. 8. Creep strain-Time curves. (a)-(c) Whole curves and (d)-(f) enlarged views at small strain and a short time range The triangles in the figure represent the creep interruption points.
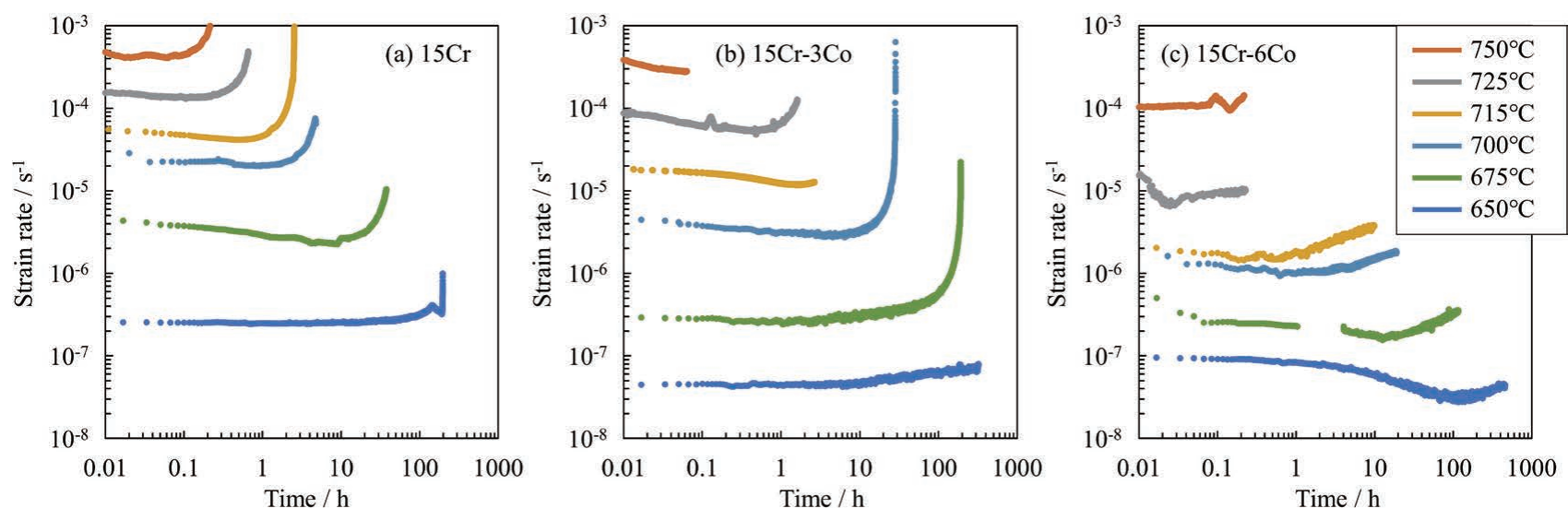

Fig. 9. Strain rate-Time curves.

Temperature $/{ }^{\circ} \mathrm{C}$

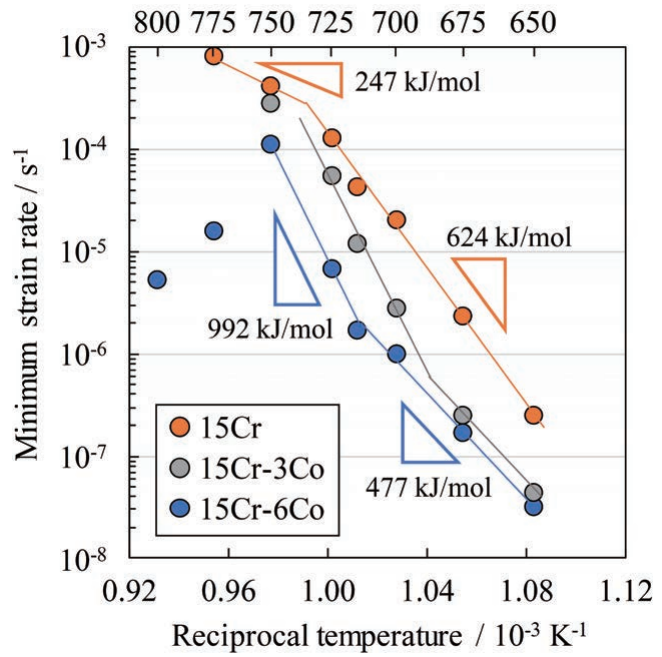

Fig. 10. Arrhenius plot of minimum strain rates. the magnetization, the changes in the ratio of the minimum strain rate and the difference in the volume magnetization with respect to temperature were compared. The results are shown in Fig. 11. The ratio of the minimum strain rate of high-creep-strength steel to that of low-creep-strength steel at the same temperature is indicated by an open symbol, and the difference in volume magnetization between the two is indicated by a blue line. From the comparison of the $15 \mathrm{Cr}$ $6 \mathrm{Co}$ and $15 \mathrm{Cr}$ steels shown in Fig. 11(a), the temperature at which the minimum strain rate ratio is the largest among the temperatures at which the creep test was performed is $715^{\circ} \mathrm{C}$. This temperature is almost the same as that where the difference in volume magnetization is the largest $\left(713^{\circ} \mathrm{C}\right)$. Since both the ratio of the minimum strain rate and the difference in the volume magnetization becomes smaller at temperatures higher or lower than this peak temperature, very good correlation is confirmed with the changes in these values. A similar tendency is observed for the comparison of 
$T_{\mathrm{C}}$

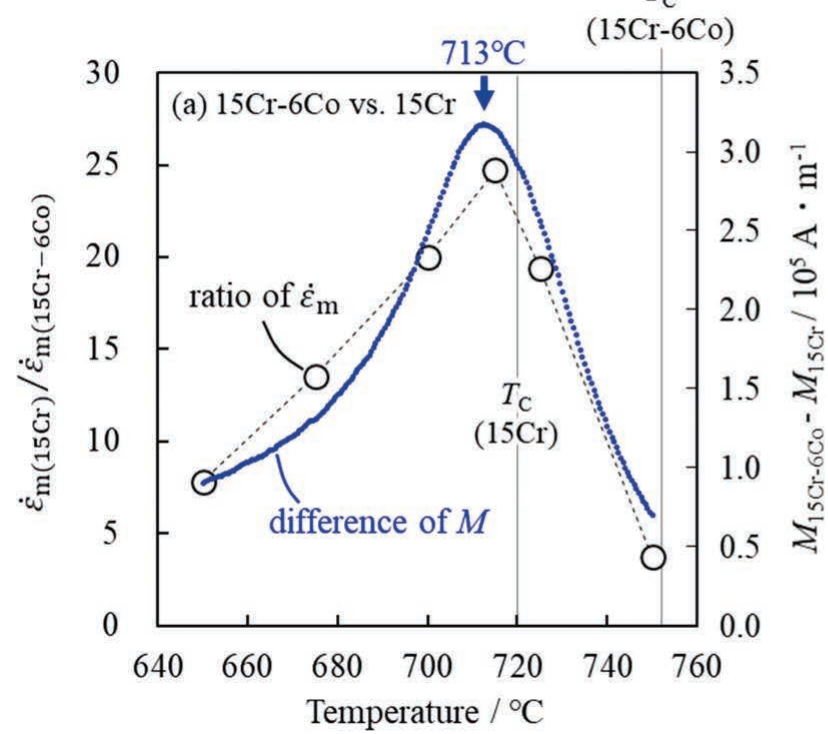

$T_{\mathrm{C}}$

$(15 \mathrm{Cr}-6 \mathrm{Co})$

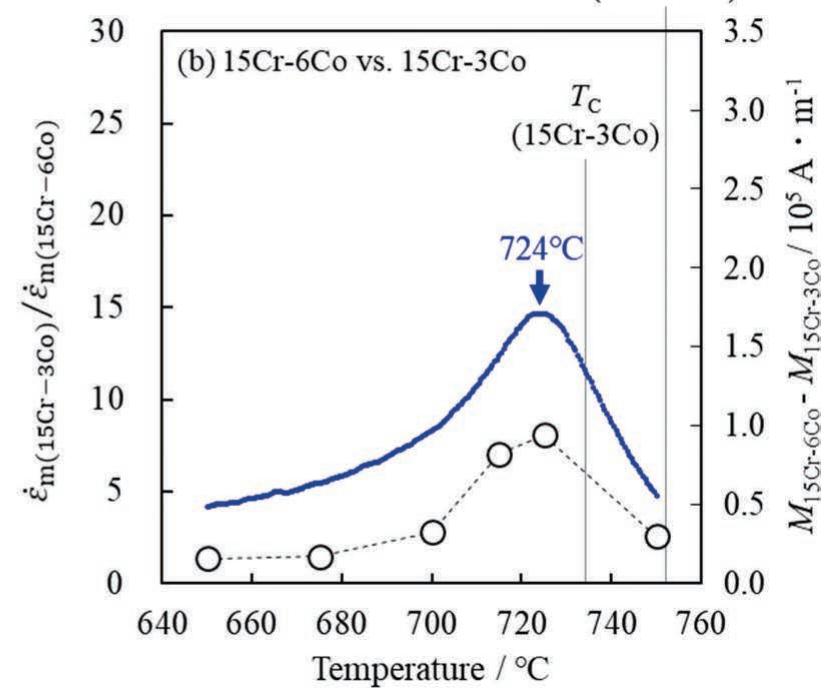

Fig. 11. Comparison of the ratio of the minimum strain rate and the difference in the volume magnetization of each sample steel: (a) $15 \mathrm{Cr}-6 \mathrm{Co}$ versus $15 \mathrm{Cr}$, and (b) $15 \mathrm{Cr}-6 \mathrm{Co}$ versus $15 \mathrm{Cr}-3 \mathrm{Co}$. (Online version in color.)

the $15 \mathrm{Cr}-6 \mathrm{Co}$ and $15 \mathrm{Cr}-3 \mathrm{Co}$ steels (Fig. 11(b)). That is, the peak temperature of the difference in volume magnetization $\left(724^{\circ} \mathrm{C}\right)$ coincides with the peak temperature for the ratio of the minimum strain rates $\left(725^{\circ} \mathrm{C}\right)$. In addition, the fact that these peak temperatures are immediately below the $T_{\mathrm{C}}$ of steels with low creep strength is also a common feature in both the $15 \mathrm{Cr}-6 \mathrm{Co} / 15 \mathrm{Cr}$ and $15 \mathrm{Cr}-6 \mathrm{Co} / 15 \mathrm{Cr}-3 \mathrm{Co}$ comparisons. In other words, this peak temperature corresponds to the temperature at which magnetism is almost lost for low-strength steel (low $T_{\mathrm{C}}$ steel), while it is maintained for high-strength steel (high $T_{\mathrm{C}}$ steel). The findings that the magnitude of creep strengthening due to Co addition differs depending on the test temperature and that a peak strength difference occurs in the intermediate temperature range cannot be explained by high temperature solid solution strengthening via the solute drag mechanism. ${ }^{45)}$ Therefore, it is likely that this tendency is due to the difference in the diffusion rate between the compared steels became maximum at the peak temperature, as a result of the reduction in the diffusion rate by the increase in the magnetization due to Co addition. These results mean that a chemical composition design that increases the magnetization of the steel at the service temperature would be useful as a new creep strengthening method for ferritic heat-resistant steel. In Fig. 11 , the value of the difference in volume magnetization is used for convenience in order to compare the magnetic properties of the sample steels. However, it is not clear what the physical meaning of this value is or whether this value is the best parameter for comparing magnetic properties related to creep strength. Further investigation is required to determine a suitable parameter for associating magnetic properties with creep strength, such as the absolute value of magnetization or the spatial distribution of magnetic domains that may affect the diffusion in steel.

\section{Conclusions}

The effect of Co addition on the creep strength of ferritic heat-resistant steel was investigated by focusing on the changes in the magnetic properties of iron due to Co. The conclusions of this study are summarized below.

(1) Co addition up to 6 mass $\%$ hardly changed the lattice constant and did not contribute to the solid solution strengthening. The addition of Co does not increase the Vickers hardness at room temperature. On the other hand, the creep strength in the temperature range from 650 to $750^{\circ} \mathrm{C}$ improved with the amount of Co added.

(2) The addition of Co increased the volume magnetization of the steel in the temperature range from room temperature to about $800^{\circ} \mathrm{C}$. The effect was greater as the amount of $\mathrm{Co}$ added increased.

(3) The ratio of the minimum strain rate and the difference of volume magnetization between steels with different Co contents underwent similar changes with temperature. These results indicate that the magnitude of the magnetization of steel is closely related to the creep strength, and the creep strength increases as the magnetization increases by Co addition.

\section{Acknowledgment}

This work was supported by the Japan Society for the Promotion of Science (JSPS) KAKENHI (Grant Number: JP19K15277).

\section{REFERENCES}

1) F. S. Buffington, K. Hirano and M. Cohen: Acta Metall., 9 (1961), 434. https://doi.org/10.1016/0001-6160(61)90137-7

2) K. Hirano, M. Cohen and B. L. Averbach: Acta Metall., 9 (1961), 440. https://doi.org/10.1016/0001-6160(61)90138-9

3) G. Hettich, H. Mehrer and K. Maier: Scr. Metall., 11 (1977), 795. https://doi.org/10.1016/0036-9748(77)90078-3

4) Y. Iijima, H. Nitta, R. Nakamura, K. Takasawa, A. Inoue, S. Takemoto and Y. Yamazaki: J. Jpn. Inst. Met., 69 (2005), 321 (in Japanese). https://doi.org/10.2320/jinstmet.69.321

5) S. Karashima, T. Iikubo and H. Oikawa: Trans. Jpn. Inst. Met., 13 (1972), 176. https://doi.org/10.2320/matertrans1960.13.176

6) R. Borg and D. Lai: Acta Metall., 11 (1963), 861. https://doi.org/ 10.1016/0001-6160(63)90055-5

7) D. J. Dever: J. Appl. Phys., 43 (1972), 3293. https://doi.org/ $10.1063 / 1.1661710$

8) K. Hirano and M. Cohen: Trans. Jpn. Inst. Met., 13 (1972), 96. https://doi.org/10.2320/matertrans 1960.13.96 
9) J. Kucera and K. Stransky: Mater. Sci. Eng., 52 (1982), 1. https://doi. org/10.1016/0025-5416(82)90067-2

10) J. Kucera, B. Million, J. Ruzickova, V. Foldyna and A. Jakobova: Acta Metall., 22 (1974), 135. https://doi.org/10.1016/0001-6160(74)90002-9

11) H. Oikawa and Y. Iijima: Creep-Resistant Steels, Woodhead Publishing, Cambridge, (2008), 250

12) K. Maruyama, K. Sawada and J. Koike: ISIJ Int., 41 (2001), 641. https://doi.org/10.2355/isijinternational.41.641

13) H. Bhadeshia: ISIJ Int., 41 (2001), 626. https://doi.org/10.2355/ isijinternational.41.626

14) A. Gustafson and J. Agren: ISIJ Int., 41 (2001), 356. https://doi. org/10.2355/isijinternational.41.356

15) K. Kubushiro, K. Nomura, T. Matsuoka, H. Nakagawa and K. Muroki: IHI Eng. Rev., 49 (2016), 34.

16) F. Abe: Engineering, 1 (2015), 211. https://doi.org/10.15302/JENG-2015031

17) M. Taneike, F. Abe and K. Sawada: Nature, 424 (2003), 294. https:// doi.org/10.1038/nature01740

18) F. Abe: J. Press. Vessel Technol., 138 (2016), 040804. https://doi. org/10.1115/1.4032372

19) A. Iseda, M. Yoshizawa, H. Okada, T. Hamaguchi, H. Hirata, K Joutoku, T. Ono and K. Tanaka: Therm. Nucl. Power Gen. Conv. Collect. Work., 12 (2016), 49 (in Japanese). https://doi.org/10.14942/ tenpes. 12.49

20) P. Yan, Z. Liu, H. Bao, Y. Weng and W. Liu: Mater. Sci. Eng. A, 588 (2013), 22. https://doi.org/10.1016/j.msea.2013.09.033

21) B. Xiao, L. Xu, L. Zhao, H. Jing, Y. Han and Z. Tang: Mater. Sci. Eng. A, 707 (2017), 466. https://doi.org/10.1016/j.msea.2017.09.086

22) H. Osawa and S. Yamda: Tetsu-to-Hagané, 49 (1963), 603 (in Japanese). https://doi.org/10.2355/tetsutohagane1955.49.3 597

23) K. Kimura, K. Seki, Y. Toda and F. Abe: ISIJ Int., 41 (2001), S121. https://doi.org/10.2355/isijinternational.41.Suppl_S121

24) Y. Toda, K. Seki, K. Kimura and F. Abe: ISIJ Int., 43 (2003), 112. https://doi.org/10.2355/isijinternational.43.112

25) L. Helis, Y. Toda, T. Hara, H. Miyazaki and F. Abe: Mater. Sci. Eng. A, 510-511 (2009), 88. https://doi.org/10.1016/j.msea.2008.04.131

26) M. Shibuya, Y. Toda, K. Sawada, H. Kushima and K. Kimura: Mater. Sci. Eng. A, 528 (2011), 5387. https://doi.org/10.1016/j. msea.2011.03.088

27) N. Dudova, A. Plotnikova, D. Molodov, A. Belyakov and R. Kaibyshev: Mater. Sci. Eng. A, 534 (2012), 632. https://doi. org/10.1016/j.msea.2011.12.020

28) A. Kipelova, M. Odnobokova, A. Belyakov and R. Kaibyshev:
Metall. Mater. Trans. A, 44 (2013), 577. https://doi.org/10.1007/ s11661-012-1390-3

29) T. Fujita: Tetsu-to-Hagané, 49 (1963), 1561 (in Japanese). https://doi. org/10.2355/tetsutohagane1955.49.10_1561

30) S. Sawa, Y. Nishi and H. Nakajima: Tetsu-to-Hagané, 50 (1964), 716 (in Japanese). https://doi.org/10.2355/tetsutohagane1955.50.4 713

31) K. Yamashita and T. Fujita: Tetsu-to-Hagané, 65 (1979), 1906 (in Japanese). https://doi.org/10.2355/tetsutohagane1955.65.13_1906

32) T. Tsuchiyama and T. Fujita: Tetsu-to-Hagané, 65 (1979), S417 (in Japanese). https://doi.org/10.2355/tetsutohagane1955.65.4 S413

33) Y. Kadoya and E. Shimiuzu: Tetsu-to-Hagané, 88 (2002), 539 (in Japanese). https://doi.org/10.2355/tetsutohagane1955.88.9_539

34) M. Arai, K. Asakura, H. Doi, $H$. Kawanaka, T. Koseki and $T$. Horiuchi: Tetsu-to-Hagané, 96 (2010), 620 (in Japanese). https://doi. org/10.2355/tetsutohagane. 96.620

35) K. Kimura, Y. Toda, H. Kushima and K. Sawada: Int. J. Press. Vessel. Pip., 87 (2010), 282. https://doi.org/10.1016/j.ijpvp.2010.03.016

36) M. Shibuya, Y. Toda, K. Sawada, H. Kushima and K. Kimura: Mater. Sci. Eng. A, 652 (2016), 1. https://doi.org/10.1016/j.msea.2015.11.068

37) I. Fedorova, A. Kostka, E. Tkachev, A. Belyakov and R. Kaibyshev: Mater. Sci. Eng. A, 662 (2016), 443. https://doi.org/10.1016/ j.msea.2016.03.092

38) B. J. Ganesh, S. Raju, A. K. Rai, E. Mohandas, M. Vijayalakshmi, K. Rao and B. Raj: Mater. Sci. Technol., 27 (2011), 500. https://doi. org/10.1179/026708309X12506933873260

39) K. Maruyama and H. Nakashima: Kouon Kyodo no Zairyo Kagaku (Material Science for High Temperature Strength), Uchida Rokakuho Publishing, Tokyo, (2002), 15 (in Japanese).

40) K. Kimura, H. Kushima, E. Baba, T. Shimizu, Y. Asai, F. Abe and K. Yagi: Tetsu-to-Hagané, 86 (2000), 542 (in Japanese). https://doi. org/10.2355/tetsutohagane1955.86.8 542

41) The Japan Institute of Metals and Materials: Kinzoku data book (Metals data book), Maruzen, Tokyo, (2004), 37.

42) W. C. Leslie: Metall. Mater. Trans. B, 3 (1972), 5. https://doi. org/10.1007/BF02680580

43) H. Oikawa: Materia Jpn., 49 (2010), 49 (in Japanese). https://doi. org/10.2320/materia.49.49

44) L. Ruch, D. R. Sain, H. L. Yeh and L. A. Girifalco: J. Phys. Chem. Solids, 37 (1976), 649. https://doi.org/10.1016/0022-3697(76)90001-9

45) H. Nakashima and H. Yoshinaga: J. Jpn. Inst. Met., 56 (1992), 254 (in Japanese). https://doi.org/10.2320/jinstmet1952.56.3 254 